Science and Technology of Welding \& Joining,

Volume 15, Number 6, August 2010, pp. 440-447

\title{
ROLLING TO CONTROL RESIDUAL STRESS AND DISTORTION IN FRICTION STIR WELDS
}

\author{
S. W. Wen*
}

Corus Research, Development and Technology, Swinden Technology Centre, Moorgate, Rotherham, S60 3AR, England, UK

\begin{abstract}
P. A. Colegrove, S. W. Williams
Cranfield University, Welding Engineering Research Centre, Building B46, Cranfield, Bedfordshire, MK43 OAL, UK
\end{abstract}

S. A. Morgan, A. Wescott

BAE Systems, Advanced Technology Centre, Filton, Bristol, BS34 7QW, UK

M. Poad

Airbus UK, Filton, Manufacturing Engineering Technology, Bristol, BS99 7AR, UK

*Corresponding author, email: shuwen.wen@ corusgroup.com 


\begin{abstract}
Considerable residual stress and distortion can be produced by Friction Stir Welding (FSW), impeding industrial implementation. Finite element analysis has been used to develop three innovative rolling methods that reduce residual stress and distortion in friction stir welds. Of the three methods, Post-Weld Direct Rolling (PWDR) where a single roller is applied to roll the top surface of the weld after the weld metal has cooled to room temperature proved the most effective. The residual stress predictions from the model compared favourably with residual stress measurements reported in an accompanying paper. Finally, the effectiveness of using PWDR is illustrated with an industrial example of a large integrally stiffened panel, where the distortion was virtually eliminated.
\end{abstract}

Keywords: Rolling, Friction stir weld, Residual stress, Distortion, Finite element modelling 


\section{INTRODUCTION}

Friction stir welding (FSW) was developed in early 1990s [1], and has been described in detail in Mishra and $\mathrm{Ma}$ [2]. The process is generally considered to have a low heat input which gives excellent mechanical properties, and low residual stress and distortion in aluminium alloys.

Although residual stress and distortion are often lower than equivalent fusion welds, they are often sufficiently high to prevent industrial application. Therefore it is necessary to understand the formation and control of residual stress and distortion. The residual stresses in FSW have been investigated by many authors including Sutton et al. [3], who carried out three-dimensional residual stress mapping of 2024-T3 aluminium alloy using the neutron diffraction technique. The largest residual stress component was found to be the longitudinal residual stress, which is generally slightly higher on the advancing than retreating side of the tool. To study the formation of residual stresses in friction stir welds Feng et al. [4] proposed an integrated thermal-metallurgicalmechanical modelling approach based on the commercial general purpose finite element (FE) code ABAQUS. Other numerical modelling and experimental work showed the influence of the welding process parameters and the release of fixtures on residual stresses in friction stir welds of stainless steel 304L [5] and aluminium alloy 2024-T4 [6].

To reduce or eliminate weld residual stress and therefore distortion, the final residual stress needs to be reduced or eliminated. This may be done by using a lower heat input process [7], stress engineering or post-processing. The stress engineering methods are those that can be used during an existing process to lower the residual stress and distortion. These methods rely on the application of a tensile stress which either reduces the compressive yielding around the weld zone or induces a tensile stretch in the material after welding [8]. Among all the stress engineering tools investigated, it appears that for friction stir welds, rolling represents the greatest potential for residual stress and distortion reduction [9-11]. This is because the technique can be relatively easily applied using the large, stiff structure provided by a typical FSW machine [11]. 
The application of rolling to reduce weld residual stress and distortion is not new. Early work in Russia [12, 13] demonstrated the effectiveness of In-Situ Direct Rolling (ISDR) which is shown in Fig. 1(b). The authors showed that the method effectively reduced residual stress and distortion and gave guidance on the design of the rolling equipment. Kurkin et al. [13] showed that the combined effect of directly rolling after the weld as well as an additional cold rolling afterwards was the most effective way to maximise the mechanical properties, and minimise distortion. Liu et al. [14] used a different rolling method, namely synchronous rolling to reduce the likelihood of hot cracking during GTAW welding of high strength aluminium alloy. The system that they employed was similar to the In-Situ Roller Tensioning (ISRT) set-up (as shown in Fig. 1(a)) that was proposed for investigation in the current study for residual stress and distortion reduction in FSW. Another technique using a trailing impact rolling device was presented by $\mathrm{Xu}$ et al. [15] for prevention of hot cracking in TIG welding of aluminium alloy thin-shell structures. This trailing impact rolling device was also used for the control of weld residual stress and distortion as well as prevention of weld hot cracking [16, 17].

In more recent work [9-11] ISRT and Post-Weld Direct Rolling (PWDR) are described. PWDR (as shown in Fig. 1(c)) is similar to ISDR, however it differs in that the rolling process is done after the component has been welded rather than in-situ. Altenkirch et al. [10] measured the residual stress and described how the method works by plastically compressing the material in the normal direction (thickness) which results in a plastic elongation in the longitudinal (rolling/welding) direction. This elongation enables the tensile longitudinal residual stress to be reduced or eliminated and where significant yielding occurs, a compressive longitudinal residual stress can be induced. Although both methods were intended to reduce distortion, Altenkirch et al. [10] found that only the PWDR was effective. Note that Altenkirch et al. [10] used the term 'PWRT' instead of 'PWDR'.

This paper will present the FE modelling used in the development of the roller system that was discussed in previous publications [9-11]. Finite Element Analysis can either be used as a 
predictive tool for use in design studies, or as a tool for post-mortem analysis. Typically, most models reported in the published literature are used for post-mortem analysis. The post-mortem model represents the actual welding conditions as near as possible, and a close match with experiments is usually found. The modelling work presented in this study was used for design purposes, so the actual FSW welding parameters, heat input, material type, and boundary conditions differed from those in the experiment. Therefore trends in the model predictions will be compared with the experimental results.

\section{METHOD}

FE models were constructed in ABAQUS and used to evaluate the three rolling methods, namely In-Situ Roller Tensioning (ISRT), In-Situ Direct Rolling (ISDR) and Post-Weld Direct Rolling (PWDR), as schematically illustrated in Fig. 1. The test plate used for the modelling analysis was 2024-T3 aluminium alloy of size $500 \times 250 \times 3.2 \mathrm{~mm}$. The temperature-dependent material properties were the same as those reported in Richards et al. [18]. The same set of data has been used for both the weld and parent material in this study and no material softening was considered for the weld metal.

Due to symmetry (the mechanical loads on the material during FSW were ignored), only half of the plate geometry was considered in the FE modelling analysis. Fig. 2 shows the FE mesh used in this study including the plane of symmetry. To minimise the CPU time, the thermal-mechanical loading during the friction stir welding and the roller tensioning/rolling processes were only applied to a $165 \mathrm{~mm}$ long section in the centre of the plate. Fig. 2 also shows how the mesh in this region was refined to a width of $60 \mathrm{~mm}$ in order to ensure the accuracy of the FE results.

In the present FE analysis, all the rolls were treated as an analytically defined rigid surface. The bottom plane of the workpiece was vertically restrained to represent the effect of the backing bar. This constraint was kept active throughout the various modelling steps for consistent residual stress evaluation. Meanwhile, symmetry boundary conditions were applied at the plane of 
symmetry as shown in Fig. 2. The FE simulation of rolling was achieved by pulling the leading edge of the workpiece (displacement controlled loading, Fig. 2) while pressing the roll against the top surface of the workpiece with a prescribed force or displacement. Coulomb friction was assumed at the contact surface between the roll and workpiece with a friction coefficient of 0.1 .

All the models of the FSW process used a welding speed was $300 \mathrm{~mm} / \mathrm{min}$ with a 5 second dwell time at the start. It was assumed that the FSW tool had a shoulder diameter of $18 \mathrm{~mm}$ with a conical pin of about $3.2 \mathrm{~mm}$ in length, and the root and tip diameter of the conical pin were respectively 4 and $2 \mathrm{~mm}$. A sequentially coupled thermal-mechanical modelling approach similar to that employed by Richards et al. [18] was adopted. In the thermal modelling that was performed first, the heat input model developed by Richards et al. [18] was modified and adjusted to match the welding conditions in the current study. A constant volumetric heat flux of $1.2 \times 10^{6} \mathrm{~kW} / \mathrm{m}^{3}$ was applied to a conical area in the weld panel directly underneath the FSW tool. In the mechanical modelling that followed, the temperature predictions from the thermal model were used to calculate the thermal load due to material expansion and contraction and hence the final residual stress. Both the thermal and mechanical models used the same FE mesh shown in Fig. 2. This modelling approach does not consider the mechanical interaction between the workpiece and the FSW tool.

The important geometric parameters for the roller designs are shown in Fig. 1 (note that the width, B and depth, D of the rolls apply equally to PWDR and ISDR) and the corresponding values used in the FE models are given in Table 1. Two conditions were used for the FE simulation of ISRT. Both conditions used a prescribed roller displacement to achieve a target rolling reduction of $0.5 \%$, but with different distances between the tool and roller, DY of $15 \mathrm{~mm}$ and $25 \mathrm{~mm}$. The $0.5 \%$ reduction corresponds to a rolling load of approximately $68 \mathrm{kN}$. Although neither of these distances could be implemented practically due to interference between the roller and FSW tool, the analysis aided understanding of the ISRT method. 
As mentioned previously, direct rolling may be applied directly after FSW tool (ISDR), or after the weld has cooled to room temperature (PWDR). In the modelling of ISDR, the roller was applied 25 $\mathrm{mm}$ behind the FSW tool with prescribed loads of 10,20 and $30 \mathrm{kN}$. Once again, this condition cannot be implemented practically due to interference between the roller and the tool. The main reasons for choosing this small trailing distance was the limited size of the model weld length (165mm). The analysis nevertheless provided a useful comparison with other rolling methods. Finally, the FE analysis was performed for PWDR with loads of $10,32.5$ and $43 \mathrm{kN}$ respectively. The results together with the workpiece deformation characteristics in terms of weld shape and rolling reduction will be discussed in the next section.

\section{RESULTS}

\section{Effect of FSW}

Fig. 3(a) shows the temperature distribution during welding predicted by the FE simulation. The peak temperature predicted by the model is just under $400^{\circ} \mathrm{C}$. This compared well with predictions made by previous investigators under similar modelling conditions [19, 20]. Colegrove et al. [19] used a simple axisymmetric flow model to predict heat generation and temperature in FSW of 3.2 mm thick 2024-T351 plate. Given the solidus temperature of alloy 2024 being $502{ }^{\circ} \mathrm{C}$, they predicted that for a travel speed of $400 \mathrm{~mm} / \mathrm{min}$ the peak temperatures in the weld root and near the tool shoulder were between 390 and $490{ }^{\circ} \mathrm{C}$ for increasing tool rotational speed from 400 to 1600 rpm. In another attempt, Schmidt et al. [20] employed a 3D FE modelling approach in order to consider the contact condition at the tool/matrix interface for heat generation. The workpiece was a $3 \mathrm{~mm}$ thick 2024-T3 plate and the welding speed was $120 \mathrm{~mm} / \mathrm{min}$ with $400 \mathrm{rpm}$ tool rotation speed. The peak temperature that they predicted was $449^{\circ} \mathrm{C}$ at the advancing side closest to the probe/shoulder corner. Although both Colegrove et al. [19] and Schmidt et al. [20] predicted higher peak temperatures during similar FSW, these were mainly confined in and near the tool/workpiece interface. Whereas the current study was focused on the bulk heating effect in the weld region during FSW. 
The FE prediction of weld longitudinal residual stress after FSW and cooling down to room temperature is shown in Fig. 3(b). The longitudinal residual stress profile across the weld at midthickness (along the path as marked in Fig. 3(b)) is plotted in Fig. 4(a). Fig. 3(b) and 4(a) shows that the weld longitudinal residual stress induced by FSW is significant, with the maximum tensile longitudinal residual stress values found near the weld approaching and even exceeding the initial yield stress (flow stress at zero plastic strain) of the weld material (250MPa). This FE prediction of residual stress profile is generally in good agreement with typical results for similar welds reported by previous researchers in the literature, in particular those by Altenkirch et al. [10] on a $5 \mathrm{~mm}$ thick 2024-T3 FSW panel (with about 190MPa maximum tensile residual stress measured in the weld) and Richards et al [18] on a 3mm thick 2024-T3 FSW panel (with about 180MPa maximum tensile residual stress predicted in the weld). Note the current prediction gives a slightly higher maximum tensile residual stress. This is partially attributed to the geometry and constraint conditions adopted in the FE model, and partially due to the fact that no material softening was included in the model which will significantly affect the result [18]. However, it should not hinder the purpose of the present investigation, which was to demonstrate the relative effect of the different rolling methods on the final residual stress distributions in the friction stir welds.

\section{Influence of ISRT}

The longitudinal residual stress profiles for both roller tensioning conditions $(D Y=15 \mathrm{~mm}$ and $25 \mathrm{~mm}$ ) evaluated along the path across the weld panel through the mid-thickness are plotted in Fig. 4(b) and compared with that of the as welded condition. The model predicted a small reduction in the longitudinal tensile residual stress in the weld region as well as significant compressive stresses either side of this. The effect of moving the roller closer to FSW tool was marginal. The average rolling force predicted by the FE simulation was about $68 \mathrm{kN}$ for both cases. The analysis also indicated that there was some minor permanent deformation produced by the rollers, which reduced the thickness by up to about $0.6 \%$ as shown in Fig. 5 . It is expected that by increasing the rolling force, the tensile residual stress in the weld could be further reduced. However, this will 
undoubtedly cause excessive deformation in the roll path which would be undesirable and complicate the weld distortion response, and therefore not recommended.

\section{Influence of ISDR}

The longitudinal residual stresses are plotted across the mid-section for the three rolling loads in Fig. 4 (c) and compared with the as-welded condition. This shows a significant reduction in tensile residual stress in the weld which increases with rolling load. Interestingly, the FE model also predicted a tensile residual stress peak away from the weld centreline, and the value of this peak decreases with the increase of the rolling load.

\section{Influence of PWDR}

The longitudinal residual stress plotted across the mid-section are shown in Fig. 4(d) for all three post welding rolling conditions and are compared with the as-welded condition. Fig. 4(d) shows that the maximum tensile longitudinal residual stress in the weld decreases rapidly with increasing rolling load. In addition, a significant amount of compressive longitudinal residual stress is produced in the weld region with the minimum value being in the centre for the lower rolling load $(10 \mathrm{kN})$ which then moves to the side of the weld centreline for the higher rolling loads (32.5 and $43 \mathrm{kN})$.

\section{The Weld Profile}

The previous section showed that the final weld longitudinal residual stress is very sensitive to the rolling force employed during the various rolling techniques, especially the ISDR and PWDR methods. It is therefore important to understand the effect of rolling on the weld profile. Fig. 5 shows a selection of the predicted change in weld panel thickness after welding and rolling. The thickness of the as-welded condition increases slightly in the weld area. This is mainly due to the restraint imposed by the surrounding material as the material expands and contracts during welding. The maximum increase is about $0.1 \mathrm{~mm}$ in the centre of the weld, which corresponds to about $3 \%$ of the initial plate thickness $(3.2 \mathrm{~mm})$. It is recognised that the actual weld profile is 
strongly influenced by the material movement and loading from the FSW tool during welding. Including this effect in the model is highly complex and so it was not considered in the simple modelling approach adapted in this work. Nevertheless this artefact of the model needs to be considered when interpreting the results.

The rolling processes all reduce the as-welded thickness increase to varying degrees, with the process that uses the highest rolling force (i.e. PWDR with $43 \mathrm{kN}$ ) also giving the largest reduction in thickness (by a maximum of about $2.5 \%$ in the weld centre, Fig. 5 ) as well as in residual stress (virtually reverted all the tensile residual stress in the weld area into compression, Fig. 4(d))..

\section{DISCUSSION}

\section{Comparison between Rolling Processes}

The FE modelling has demonstrated that each of the three rolling methods can effectively reduce the as-welded residual stress, and of the three methods, PWDR is the most effective. The reduction in longitudinal residual stress with ISRT (Fig. 4(b) was marginal (about 20\%) indicating that the amount of roller tensioning in the weld region was minimal. More interestingly, the model also predicted a large compressive region beside this, which was undoubtedly produced by the rollers compressing this material. This compressive stress was sufficiently large to produce a small tensile stress in the far field, i.e. at distances greater than $40 \mathrm{~mm}$. Although distortion was not predicted by the model, it could be significantly reduced by ISRT because buckling distortion will be inhibited by the tensile stresses to either side of the large compressive region.

The ISDR results in Fig. 4(c) show a more significant reduction in the longitudinal residual stress in the centre of the weld area, although the peak value with the $10 \mathrm{kN}$ load is very similar to the aswelded condition. The peak tensile residual stress decreases rapidly with the increase of the ISDR load. In addition, the location of the peak also moves away from the weld centreline as the ISDR load increases from $7 \mathrm{~mm}$ at $10 \mathrm{kN}$ to $12 \mathrm{~mm}$ at $30 \mathrm{kN}$. The latter result is likely to be an artefact of the thickness change predicted by the model in the as-welded condition (Fig. 5), i.e. after welding 
the thickness of the material increases. Therefore, when the roll is applied to the weld, the greatest load and greatest deformation will be along the weld centreline, i.e. the deformation will not be applied uniformly under the roller. This is the cause of the higher reduction in longitudinal residual stress along the weld centreline. Nevertheless, it is interesting to note that, unlike PWDR which gives a high compressive residual stress in the rolled (weld) area, ISDR can give minimal (close to zero) longitudinal residual stress levels in the rolled area. As shown in Fig. 4(c), for the 30kN rolling force case it may be possible to further eliminate the spike in the longitudinal residual stress profile near the edge of the rolling path by a specific roller design and loading strategy, and thus produce an ultimate residual stress free weld.

The results for the $10 \mathrm{kN}$ force PWDR in Fig. 4(d) are similar to the ISDR results in that there is a minimum value along the weld centreline, followed by a tensile peak $8 \mathrm{~mm}$ away from the weld centreline. The cause is likely to be the same as for ISDR. The main difference with the ISDR results is the significantly lower longitudinal residual stress predicted along the weld centreline for the same rolling load, i.e. -220MPa vs $40 \mathrm{MPa}$. On first inspection this is perhaps a little surprising as one may have expected greater deformation of the weld region with the hot, soft material in ISDR. This is indeed reflected in the plot of the thickness change in Fig. 5. However, it must be remembered that the material is rolled while it is still relatively warm, so the material will contract (causing a tensile stretch) as it cools to room temperature. Therefore the predicted longitudinal residual stress with ISDR is higher than PWDR.

The tensile peak away from the weld is eliminated with higher rolling loads with PWDR. In this case the roller load is likely to be sufficiently high to obtain full contact with the plate, resulting in a more uniform stress state underneath the roller. The cause of the small rise in longitudinal residual stress along the weld centreline, which is particularly noticeable with the highest $(43 \mathrm{kN})$ load is unclear.

\section{Comparison with Experiments}


As mentioned earlier, the residual stress of rolled welds has been measured by neutron diffraction by Altenkirch et al. [10] for similar friction stir welds with both the ISRT (5mm thick 2024-T3 alloy) and PWDR (5mm thick 2199-T8) methods. Unlike the FE modelling results, the experiments showed that ISRT had no effect on the final longitudinal residual stress distribution in the weld [10]. To understand why this may be the case, Table 2 compares the materials and rolling conditions used in the experiments with those used in the FE modelling. There are obviously many differences, but the most significant one is the trailing distance between the weld and rollers. In the model this was varied between 15 and $25 \mathrm{~mm}$, while the minimum distance that could be achieved in practice was $40 \mathrm{~mm}$. As stated in Altenkirch et al. [10] this greater distance, in combination with the cooling effect of the rollers themselves (which is not considered in the model) is likely to mean that the material will be too cool to plastically yield in the experiments. This is supported by the fact that no significant and consistent compressive residual stress was observed in the rolling path [10]. Further increasing the rolling load may cause plastic deformation in the material and hence result in the beneficial effects, however this was not attempted due to the overall loading capacity of the FSW machine being reached.

Better agreement was obtained between the PWDR experimental, as shown in Fig. 6, and modelling results, Fig. 4(d). Although there were differences in the detail of the longitudinal residual stresses predicted which could be due to the different materials and thickness used, there was broad agreement in the following aspects:

- Increasing compressive stress with the increase of the applied load, although once it reaches a minimum value no further reduction was achieved.

- A widening of the compressive stress area produced by the roller as the roll load increased.

- A tensile longitudinal residual stress region to either side of the central compressive longitudinal residual stress region. 
With respect to the last point, the previous section has already described how this is likely to be caused by the camber on the top surface of the weld predicted by the model. This may also be the cause of the effect in the experiments, although the material movement induced by the tool shoulder will probably lead to a flatter surface than in the model, so the effect is less pronounced. To obtain a more even longitudinal residual stress profile, a slightly profiled roller could be introduced accordingly in order to induce more uniform deformation across the weld.

Finally Kurkin et al. [13] compared the reduction in distortion of ISDR with PWDR and showed that the latter produced the largest reduction in distortion. This confirms the finding of the current FE model which predicted that the final residual stress was lower for PWDR with equivalent rolling load.

\section{APPLICATION TO A LARGE AEROSPACE COMPONENT}

Because of the effectiveness of the PWDR method shown by the FE simulation, the technique was applied to the FSW of a large integrally stiffened panel for the manufacture of an aerospace component. The initial single panel size was $3.8 \times 0.228 \mathrm{~m}$ and six of these were welded together to produce the final $3.8 \times 1.37 \mathrm{~m}$ panel. After FSW, the panel had more than $21 \mathrm{~mm}$ out-of-plane distortion (Fig. 9), causing difficulty when subsequently machining the panel to shape. To eliminate the distortion, the five welds were sequentially rolled. Fig. 7 shows the test set-up just before the start of the PWDR process with the direction and sequence of the FSW and PWDR clearly marked. A close-up view of the roller system is given in Fig. 8. Fig. 9 gives the result from the distortion assessment of the full panel joined with FSW before and after PWDR, showing clearly the effectiveness of the rolling process in reducing the weld distortion (from a maximum out-of-plane distortion of more than $21 \mathrm{~mm}$ down to less than $3.5 \mathrm{~mm}$ ). After rolling, the panel appeared virtually flat considering its size and was easily machined to the designed component shape, and no additional distortion was produced by the machining process.

\section{CONCLUSIONS}


FE models of three rolling methods, namely ISRT, ISDR and PWDR, have been applied to roll friction stir welds and used to understand the reduction in residual stress induced by FSW. There was a reduction in the longitudinal residual stress with all methods which increased with the increase in rolling load. Of the three methods PWDR was the most effective. This method is also easier to implement in practice. An experimental investigation in an accompanying paper [10] confirmed that PWDR was the more effective method and broadly confirmed the changes in longitudinal residual stress with similar rolling forces as those employed in the modelling analysis of this study. The experiments indicated that ISDR had no effect on the longitudinal residual stress, unlike the model which indicated a small reduction.

Finally the success of PWDR led to the implementation of the technique on a large integrally stiffened panel joined by FSW for aerospace applications. This work showed a significant reduction in the weld distortion. It is believed that PWDR will be an enabling technology for the implementation of FSW in the aerospace sector.

\section{ACKNOWLEDGEMENT}

The authors gratefully acknowledge funding form the Technology Strategy Board.

\section{REFERENCES}

1. W. M. Thomas, E. D. Nicholas, J. C. Needham, M. G. Murch, P. Temple-Smith, and C. J. Dawes, 1995, 'Friction stir butt welding', Int. Patent Application No. PCT/GB92/02203; GB Patent Application No. 9125978.8, 1991; US Patent No. 5460317, 1995.

2. R. S. Mishra and Z. Y. Ma, 'Friction stir welding and processing', Materials Science and Engineering R: Reports, 2005, 50, 1-78P.

3. M. A. Sutton, A. P. Reynolds, D. Q. Wang and C. R. Hubbard, 'A study of residual stresses and microstructure in 2024-T3 aluminium friction stir butt welds', Journal of Engineering Materials and Technology, Transactions of the ASME, 2002, 124, 215-221. 
4. Z. Feng, X. Wang, S. A. David and P. S. Sklad, 'Modelling of residual stresses and property distributions in friction stir welds of aluminium alloy 6061-T6', Science and Technology of Welding and Joining, 2007, 12, 348-356.

5. X. K. Zhu and Y. J. Chao, 'Numerical simulation of transient temperature and residual stresses in friction stir welding of 304L stainless steel', Journal of Materials Processing Technology, 2004, 146, 263-272.

6. T. Li, Q. Y. Shi and H. Li: 'Residual stresses simulation for friction stir welded joint', Science and Technology of Welding and Joining, 2007, 12, 664-670.

7. P. A. Colegrove, C. Ikeagu, A. Thistlethwaite, S. W. Williams, T. Nagy, W. Suder, S. Steuwer and T. Pirling, 'The welding process impact on residual stress and distortion', Science and Technology of Welding and Joining, 2009, 14, 717-725.

8. D. A. Price, S. W. Williams, A. Wescott, C. J. C. Harrison, A. Rezai, A. Steuwer, M. Peel, P. Staron and M. Kocak, 'Distortion control in welding by mechanical tensioning', Science and Technology of Welding and Joining, 2007, 12, 620-633.

9. S. W. Williams, S. A. Morgan, A. Wescott, M. Poad and S. W. Wen, 'Stress Engineering Control of Residual Stresses and Distortion in Welding', Proc. 2nd International Workshop on 'Thermal Forming and Welding Distortion', Bremen, Germany, April 22-23, 2008.

10. J. Altenkirch, A. Steuwer, P. J. Withers, S. W. Williams, M. Poad and S. W. Wen, 'Residual stress engineering in friction stir welds by roller tensioning', Science and Technology of Welding and Joining, 2009, 14, 185-192.

11. S. W. Wen, S. W. Williams, S. A. Morgan, A. Wescott, M. Poad and G. Moor, 'Rolling of friction stir welds for residual stress and distortion control', Proceedings of the $9^{\text {th }}$ International Seminar on Numerical Analysis of Weldability, Graz, Austria, 28-30 September 2009.

12. S. A. Kurkin and V. I. Anufriev, 'Preventing distortion of welded thin-walled members of AlMg6 and 1201 aluminum alloys by rolling the weld with a roller behind the welding arc', Welding Production (English Translation of Svarochnoe Proizvodstvo), 1984, 31, 52-55. 
13. S. A. Kurkin, V. I. Anufriev and E. S. Milekhin: 'Improving the mechanical properties of welded joints in the AMg6 alloy by plastic deformation during arc welding', Welding Production, 1980, 27, 20-24.

14. W. Liu, X. Tian and X. Zhang, 'Preventing weld hot cracking by synchronous rolling during welding', Welding Journal (Miami, Fla), 1996, 75, 297-s.

15. W. Xu, C. Fan, H. Fang and X. Tian, 'New development in welding thin-shell aluminum alloy structures with high strength', China Welding (English Edition), 2004, 13, 27-30.

16. C. Fan, H. Fang, J. Tao and X. Wang, 'Strain field analysis of welding with trailing impact rolling for reduction of residual stress and distortion and prevention of hot cracking', Transactions of the China Welding Institution (in Chinese), December 2004, Vol. 25, No. 6, pp. 47 - 50.

17. C. Fan, H. Fang, J. Tao, Y. Tian and M. Li, 'Weld with trailing impact rolling to control the residual distortion of the thin-walled planar circumferential weldment', Journal of Harbin Engineering University (in Chinese), Vol. 26, No. 2, April 2005, pp. $238-241$.

18. D. G. Richards, P. B. Pragnell, P. J. Withers, S. W. Williams, A. Wescott and E. C. Oliver, 'FE Modelling of Mechanical Tensioning for Controlling Residual Stresses in Friction Stir Welds', Materials Science Forum, 2007, 539-543, 4025-4030.

19. P. A. Colegrove, H. R. Shercliff and R. Zettler, 'Model for predicting heat generation and temperature in friction stir welding from the material properties', Science and Technology of Welding and Joining, 2007, 12, 284-297.

20. H. Schmidt, J. Hattel and J. Wert, 'Modelling of the contact condition at the tool/matrix internface in friction stir welding', Mathematical Modelling of Weld Phenomena 7, 2005, 925-941. 